\title{
Teaching Foreign Languages Through Culture
}

\author{
PhD. Cand. Arti Omeri \\ Department of English Language and Literature, \\ Faculty of Philology and Education \\ Bedër University, Tirana, Albania \\ artomeri@hotmail.com \\ aomeri@beder.edu. al
}

\begin{abstract}
The word is becoming globalized in every aspect. As a result, people are encountering everyday many foreign languages and cultures either through mass media, social media, schools, books etc. Living in this type of environment gives us the opportunity to learn and study many foreign languages and cultures. The importance of the relation between language and culture has been studied and assessed since a long time. This study is focused on how foreign languages are taught through culture. There can be raised several important question regarding the relation between language and culture. Is there any connection between language and culture? Do they influence one another? Can someone learn a language without knowing the culture and vice versa? In order to answers such questions there was revised the most modern literature on this topic. After revising the literature, a survey was also conducted to the lecturers and students of foreign languages faculty at "Aleksander Xhuvani" University in Elbasan. The purpose was to approach the topic from both perspectives and get the results and opinions from different point of views. The number of students participating in the survey was higher than lecturers, so percentages are given separately for both categories. Then the results were analyzed and compared with one another.
\end{abstract}

Keywords: Language, Culture, Foreign languages, Effective communication, Cultural barriers, Education.

\section{Introduction}

The relation between language and culture has long been studied and analyzed. According to Timpe it is essential to consider the relationship between language and culture in order to obtain a better idea of the close and mutually-influential interconnectedness between language and culture. It is only through language that a person is able to access the foreign culture and enter the realm of the new cultural territory (Timpe 2014, p. 13). Hence, both language and culture are inextricably linked, as one does not function without the other (Timpe 2014, p. 15). So, here the importance of studying both language and culture is highly emphasized. Timpe claims that one cannot study the foreign culture without studying the language. They are very closely connected an inseparable from one another.

Kinginger claims that there is great interest in 'teaching culture' as a part of the second language learning project. Even though, he continues that language and culture are not included in the same second language curricula, study abroad programs, and other learners and researchers programs. Kinginger insists that in the broader field of teacher education, the attention should be focused on the barriers that culture can create on effective teaching while teaching a foreign language. It influences the teacher's performance. (Kinginger, 2013, p. 76). As a result culture and language should be studied in the same language curricula. To avoid the barriers in teaching performance the teacher should be well aware of cultural differences and should include culture in their everyday language teaching activities. 
Hager suggests that culture and language are closely knit and that they need to be taught/learned simultaneously (Hager 2011, p. 3). The semantics of grammar are loaded with cultural values and ideas; this can be found in the social structures speakers use, e. g. the social organization of speech communities (Hager 2011, p. 37). So, it is of great importance to study them at the same time. You may not understand the language without the culture as culture takes part in all aspect of the language including grammar and social structures.

It is impossible to translate the languages word for word. According to Reid all languages have idiomatic expressions which carry cultural connotations that are beyond the meanings of the individual words. As such it becomes impossible to translate appropriately without any cultural knowledge. Reid also claims that each language and culture is concerned with gestures and body movements which also importantly convey meaning. Gestures and body movements do not al-ways mean the same in different languages and cultures (Reid 2014, p. 25). So in order to avoid misunderstanding one should also study other aspect of communication such as body language.

If we are unfamiliar to a language and culture it would be even more difficult to understand a text in that language. Matos emphasizes that if the readers we have in mind are reading in a foreign language and that if both the culture and the language are foreign in the perspective of these readers, learners may experience greater difficulty in identifying potential meanings in a given context (Matos 2012, p. 59). Being unfamiliar with both language and culture makes it quite difficult to understand a context in that foreign language.

Some people show interest on a language just because of its culture. If it is a dominant or a popular culture people may be encouraged to start learning the language of that culture. James and Georgieva said that speaking the language of a popular culture may be associated with prestige, and be valued by younger people (James \& Georgieva, 2010, p. 5).

According to Putz teachers are unaware of the culture they transmit while teaching a language. After conducting a survey with several lecturers he concluded that all lecturers are of the opinion that language teachers are generally un-aware of the culture that they transmit when they teach a language. As one lecturer put it, "We think in our culture and we transmit this in our teaching, but we are unaware" (Puitz,. 1997). The teachers should be aware of the culture and messages they transmit and should be aware of the culture of their students.

Zarobe, Y., \& Ruiz de Zarobe, L argue that contemporary linguistics and communication practice have shown that cultural contact occurs simultaneously with language contact, and therefore understanding cultural contact is essential for setting up efficient communication among members of different cultures Ruiz de Zarobe, Y., \& Ruiz de Zarobe, L. 2012, p. 337). As a result knowing the culture is a key factor for achieving effective communication.

\section{Method}

This research was conducted at "Aleksander Xhuvani" University in Elbasan. A questionnaire composed of ten questions was prepared and distributed to students and lecturers of the foreign language faculty of this university. There were asked the same questions for both categories in order to get the answers and opinions from different point of views. The results of both groups could be contrasted and compared. Some of the questions were open ended and some closed ended, so that it made it possible to conduct a qualitative and quantitative analysis on this topic. This study was about teaching foreign languages through culture, so the students and lecturers involved were not just part of one department. It included students learning English, French, German, and Italian. For the study it did not matter what department belonged each student as the culture and language relation is almost equally important for all languages. The questionnaire was anonymous and each participant was given enough time and explanation to complete the survey. In total there were 100 students and 10 lecturers involved in the research. Each of them answered and submitted the following questionnaire.

Do you think culture and language are connected with each other?

Can someone learn the language without learning the culture or vice versa?

Can language and culture function without each other?

Can culture be a barrier to language learning performance? 
When learning a foreign language, is it necessary to learn culture and the language simultaneously?

Does culture influence the grammar of a language?

Is the body language the same in all cultures?

Will you ever study a foreign language because of its culture?

Can a language be translated word for word?

What do you think about the role of culture in effective communication?

\section{Results}

Analyzing the questionnaire was the next step in this research. Regarding the question about the connection between culture and language all the lecturers and $85 \%$ of the students agreed that there is a connection between the two. The rest of the students either claimed that they did not know the answer or they said that there was no connection between them. As it is shown from the results the vast majority of student and lecturers believe that there is a relation or a strong relation between language and culture that is worth studying.

The next question asked for the opinion whether a language or culture could be learned separately. Most of the lecturers $80 \%$ think that language cannot be learned without culture and $90 \%$ of them think that a culture cannot be studied without knowing that language. The percentages were a little lower when it came to students results. $60 \%$ of students think that a language cannot be learned without culture and $65 \%$ think that a culture cannot be learned without knowing the language.

Again all the lecturers agreed that language and cultures cannot function without each other. Surprisingly here even the number of students who think the same way as their lecturers was too high. $97 \%$ of students declared that both language and culture do not function without each other.

The following question was about barriers that a culture can cause in language learning. Most of the teachers agreed that a culture can be a serious barrier $60 \%$ to language learning whereas other $30 \%$ said that it can cause some difficulties. Only one lecture, $10 \%$ responded that the culture cannot be a barrier to language learning. On the other side only $40 \%$ of students said that the culture can be a real barrier to language learning. The other $35 \%$ claimed that it can cause some problems and the remaining $25 \%$ did not consider culture as a barrier at all.

The answers of the following questions were not easy to be analyzed as there were various types of responses. Nevertheless, most of lectures, $70 \%$ insisted on learning language and culture simultaneously. On the other hand the students did not produce solid results like lecturers. If answers without any relevance to the study are excluded then the result was $37 \%$ declaring that language and culture should be studied simultaneously, $28 \%$ said that it does not matter which one you study first and another $25 \%$ did not know or did not answer the question.

In the question asking about the influence of culture in the grammar both students and lecturers, $83 \%$ and $90 \%$ respectively, were certain that there was a kind of influence coming from culture. Most of the lecturers also gave concrete examples were culture influenced grammar as in the example of gender categories.

The only question which had a unanimously response was whether the body language was the same in all cultures. Here lectures and students all agreed that body language differed from culture to culture. Body language is a very import aspect of communication. As a result one should know very well the body language of another culture in order to communicate appropriately. The importance of culture in language and communication is best understood from the results to this question.

The next question asked lecturers and students whether they will study a foreign language just because of its culture. Only $40 \%$ of lecturers and $26 \&$ of students claimed that they will study a language in the future just because they are interested or encouraged by its culture. Even though the results may seem low, still there are a significant number of students and 
lecturers who want to study a language just to know or become familiar to its culture. Considering that there is an unlimited number of reasons to study a foreign language cultural reasons seems to be considered quite high.

The following question asked the two groups whether a foreign language can be translated word for word in the mother tongue. All the lecturers unanimously responded that a foreign language cannot be translated word for word as you need to know the culture, idioms and expressions of both languages in order to make an appropriate translation. $82 \%$ of students also claimed that word for word translation is either wrong or impossible. Only $18 \%$ of the students agreed that word for word translation is possible or is the same in different languages. The results of this question show once again the importance of knowing language and culture at the same time in order to have a better understanding or translating 0 foreign language.

Regarding the last question we may say that the responses varied considerably as it was an open ended questions. Most of the lecturers, $90 \%$, considered the role of culture in communication either as important or very important. As they defined communication as something larger than language which includes it, they declared that the role of culture in communication was even higher. $75 \%$ of students also defined the role of culture in communication as important. Even the rest of the students, who did not emphasize the role of culture, accepted that there is some importance of cultural knowledge in communication.

\section{Discussion}

After analyzing the results, based on the majority of the responses, it can be said that the language and culture are closely connected with one another. As a result a language cannot be learned without knowing the culture and vice versa. They cannot function without one another. Not knowing a culture can a barrier when studying a foreign language. In order to avoid such problems one should study also the culture related to that language. So, when learning a foreign language it is necessary to study both the language and the culture simultaneously.

The culture of a nation can influence the grammar of the language, its vocabulary, and the body language. As it can be seen the impact of the culture in the language is enormous. There cannot be an appropriate communication or understanding without knowing both of them. We may misunderstand other people just by not being familiar to their culture. It would be impossible to translate a foreign language to a mother tongue without any knowledge about the culture as word for word translation most of the times is impossible. Culture has a great influence in learning a foreign language. Many people start learning a new language just because they interested about the culture of that nation.

\section{Conclusion}

To conclude it can be said that language and culture relation is very important when considering studying a new language. One may not succeed in learning a language without studying its culture simultaneously. Cultural aspects can be the main barriers of communication between individuals. Body language, grammar, vocabulary, idioms, and politeness they all change from culture to culture. It is almost impossible to have a good knowledge of language without all these components. Even if you know a lot of vocabulary of a foreign language you are most likely going to misunderstand and misinterpret their language if you do not have any knowledge about their culture and tradition.

It is strongly advisable that someone should study both the language and the culture of a target language as they cannot function separately. It is very important to become familiar with the culture in order to progress or improve the language capabilities. Nowadays many texts include cultural aspects when designing the curricula of a language program. Language and culture are said to be mutually influential and very closely connected to one another.

\section{Bibliography}

Timpe, V. (2014). Assessing Intercultural Language Learning : The Dependence of Receptive Sociopragmatic Competence and Discourse Competence on Learning Opportunities and Input. Frankfurt: Peter Lang AG.

Kinginger, C. (2013). Social and Cultural Aspects of Language Learning in Study Abroad. Amsterdam: John Benjamins Publishing Company. 
Hager, M. (2011). Culture, Psychology, and Language Learning. Oxford: Peter Lang AG.

Reid, E. (2014). Intercultural Aspects in Teaching English at Primary Schools. Frankfurt: Peter Lang AG.

Matos, A. G. (2012). Literary Texts and Intercultural Learning : Exploring New Directions. Oxford: Peter Lang AG.

James, A., \& Georgieva, M. (2010). Globalization in English Studies. Newcastle: Cambridge Scholars Publishing.

Puitz, M. (1997). The Cultural Context in Foreign Language Teaching. Frankfurt am Main: Peter Lang AG.

Ruiz de Zarobe, Y., \& Ruiz de Zarobe, L. (2012). Speech Acts and Politeness Across Languages and Cultures. Bern: Peter Lang AG. 